\title{
Article
}

\section{What do people infer from facial attractiveness?}

Brewer, Gayle and Archer, John

Available at http://clok.uclan.ac.uk/548/

Brewer, Gayle ORCID: 0000-0003-0690-4548 and Archer, John ORCID: 00000003-0483-1576 (2007) What do people infer from facial attractiveness? Journal of Evolutionary Psychology, 5 (1). pp. 39-49. ISSN 1789-2082

It is advisable to refer to the publisher's version if you intend to cite from the work. http://dx.doi.org/10.1556/JEP.2007.1002

For more information about UCLan's research in this area go to

http://www.uclan.ac.uk/researchgroups/ and search for < name of research Group>.

For information about Research generally at UCLan please go to http://www.uclan.ac.uk/research/

All outputs in CLoK are protected by Intellectual Property Rights law, including Copyright law. Copyright, IPR and Moral Rights for the works on this site are retained by the individual authors and/or other copyright owners. Terms and conditions for use of this material are defined in the policies page.

\section{CLoK}

Central Lancashire online Knowledge www.clok.uclan.ac.uk 


\title{
WHAT DO PEOPLE INFER FROM FACIAL ATTRACTIVENESS?
}

\author{
G. BREWER ${ }^{1}$, J. ARCHER \\ University of Central Lancashire, Preston, UK
}

\begin{abstract}
The facial photographs of 84 heterosexual women were rated for attractiveness by 74 males and 74 females who also made judgements regarding the personality and behaviour of these women. Both sexes judged physically attractive women as possessing more desirable personality traits and also as being more promiscuous than less attractive women. These findings extend the beauty-is-good stereotype, also attributing a more unrestricted sexual strategy to attractive women. This is consistent with research identifying the actual strategies of attractive women. It is argued that both sexes would benefit - in terms of mate choice and identification of rivals - from identifying attractive women as likely to be more promiscuous.
\end{abstract}

Keywords: personality, stereotype, promiscuity, attractiveness

\section{INTRODUCTION}

One of the most consistent findings in the field of person perception concerns the 'what is beautiful is good' (DION, BERSCHEID and WALSTER 1972) or 'halo' effect (NISBETT and WILSON 1977) whereby those with a high level of physical attractiveness are deemed to posses a greater number of socially desirable personality traits than those with a lower level of attractiveness. Focusing on the perceptions of observers toward target strangers, EAGLY et al. (1991) suggested that the stereotype may not be as strong or as consistent from study to study as initially implied with the type of judgment that observers are asked to make, accounting for

\footnotetext{
${ }^{1}$ Corresponding author: G. BREWER, Department of Psychology, University of Central Lancashire, Preston Lancashire PR1 2HE, UK. E-mail address: GBrewer@UCLan.ac.uk, Fax number: 01772892925.
} 
a significant degree of this variation. The stereotype is not limited to stranger attributions. In a meta-analysis of over 900 studies in this area, LANGLOIS et al. (2000) concluded that attractive individuals are attributed with a number of desirable personality traits regardless of their relationship with the observer. As the physical attractiveness of a target influences both the perception of an observer and their behaviour towards the target, there are important implications for interpersonal relationships.

DERMER and THIEL (1975) show that while beauty is typically associated with a number of positive traits, it is also related to a number of negative behaviours such as the tendency to be vain, egoistic and have an extra-marital affair. Therefore physical beauty may be associated with the possession of both positive and negative personality traits and behaviours. If a person is expected to possess particular personality traits, an observer's behaviour towards them may be altered accordingly. SNYDER, BERSCHEID and TANKE (1977) showed that men who believed that they were talking to a physically attractive woman were (as judged by independent raters) more sociable, sexually warm, interesting, independent, sexually permissive, bold, outgoing, humorous and socially adept.

Although the relationship between attractiveness and judged personality is a robust finding, demonstrated in a number of contexts, it is not primarily a theoretically-driven finding. Here we propose that inferences about a potential mate's personality and sexual behaviour may have a clear functional basis. The basis for this proposition primarily concerns the sexual strategies adopted by each sex and the preference for specific partner traits (Buss and SCHMITT 1993). The functional basis for these judgments may help resolve the apparent contradiction in the attribution of both positive (DION et al. 1972) and negative (DERMER and THIEL 1975) personality traits to attractive individuals. In particular, it is suggested that these judgments may help men identify a suitable mate or direct mate guarding tactics and help women identify the rivals that pose the greatest threat to their current relationship.

One of the most prominent differences between male and female sexual strategies is the greater male preference for short-term relationships and the greater female preference for long-term relationships (Buss and ScHMITT 1993) traditionally explained in terms of maximum male and female reproductive output and differential levels of minimum parental investment (BATEMAN 1948, TRIVERS 1972). Research in this field supports the contention that women have a greater preference for long-term relationships than men, demand a higher level of commitment, and are in general more selective in their choice of partner (Buss and SCHMitT 1993; ClARK and HATFIELD 1989). However, a number of possible advantages to short-term relationships for women have been investigated (GREILING and BUSS 2000), including the resource, genetic, mate switching, mate skill acquisition, and mate manipulation hypotheses. These suggest that in particular circumstances it may be beneficial for women to adopt a short-term strategy. 
MIKACH and BAILEY (1999) have found that women with a physically attractive body shape (designated by a low waist-to-hip ratio, SINGH 1993) follow a more unrestricted (short-term) sexual strategy than women with a less attractive figure. The desirability of these women ensures that they remain desirable to men and compensates for the disadvantages associated with the selection of a potentially promiscuous partner. Furthermore, SINGH (2004) showed that both men and women expect women with an attractive body shape to be less faithful than less desirable women, suggesting that other individuals are aware of a relationship between attractiveness and promiscuity. Despite expecting women with an attractive body shape to be less faithful than their less attractive counterparts, men rated these women as more desirable. Thus physically attractive women would be able to enjoy the benefits of short-term relationships and remain attractive as a long-term partner. In Singh's study, women's attractiveness was assessed by body shape. The present study employs ratings of facial photographs taken from a naturally occurring sample as an index of attractiveness. This represents a more direct assessment of women within their peer group.

Due to the high levels of minimum maternal investment (TRIVERS 1972), the level of investment contributed by men has a significant influence on the welfare of the woman and her offspring. Women who are able to encourage this investment and avoid desertion would be at a distinct advantage. In particular, the presence of rival females, which could prompt men to withdraw previous investment, should be closely monitored. Mate poaching may be a widely used (and often successful) method of partner attraction (SCHMITT and BUSS 2001). Therefore reproductive rivals represent a considerable threat to an existing relationship.

A number of variables could increase the likelihood that men will transfer their attention (and investment) to a rival female. These include her physical attractiveness, indicating her overall mate value, and possibly also signalling her preferred (short-term) sexual strategy. Men may be willing to offer physically attractive women a greater level of investment (due to their high mate value) and thus they represent the greatest threat to other women. Men may be more willing to abandon a previous mate or take greater risks due to the higher relative attractiveness of the rival female. For women not in a relationship, attractive women may threaten the ability to attract a desirable partner. It is predicted that although male and female observers will rate physically attractive women as more likely to possess desirable personality traits, observers will also judge these women to be more promiscuous. Male observers will rate physically attractive women as more desirable for a relationship but female observers will be unwilling to accept them within the social group. 


\section{METHOD}

\section{Female targets}

84 female students were recruited from the University of Central Lancashire. Participants were required to be heterosexual, not pregnant or breast feeding and aged between 18 and 35. The mean age of the female targets was 20.37 (range 18-33, SD 2.69). Facial photographs of each participant were taken using a Mavica digital camera (at a resolution of $640 \times 480$ pixels). Women were asked to stand against a white background, look directly at the camera and adopt a neutral expression. The photographs were later rated by men and women (on a scale of 17) that had no information about the target female other than the facial photograph. This contrasts with much of the previous research in which individuals are categorised as high and low attractiveness only (LANGLOIS et al. 2000). The present study was part of a larger investigation containing a number of other measures designed to address a number of hypotheses (BREWER 2006).

\section{Male observers}

74 heterosexual men were recruited from the University of Northumbria. The age of male observers was 22.13 (range 18-68, SD 7.44). Participants were presented with a booklet containing colour facial photographs of target women (sized $29 \mathrm{~cm} \times 20 \mathrm{~cm}$ ) and were asked to first rate the targets for physical attractiveness on a scale of 1-7 and then on 22 items relating to their perceptions of these women and predicted behaviour towards her.

A principal components factor analysis with Varimax orthogonal rotation conducted on the 22 items presented to male observers identified three factors (with eigenvalues $=>1.00$ ), from which three sub-scales were devised. The items loaded onto each factor above a value of .4 were added together to constitute each subscale. The first factor contained 6 items and measured the woman's desirability for a relationship. Items contained in the sub-scale included willingness to introduce the woman to his family and predicted spend on a first date. The second factor contained 7 items including faithful, feminine, and trustworthy, and measures the woman's possession of desirable personality traits. The third factor contained 4 items, including promiscuous and sexually experienced, and this sub-scale measures overall promiscuity. These factors explained $58 \%, 22 \%$ and $6 \%$ of rating variance respectively. See Table 1 for full details of each subscale. 
Table 1. Subscales derived from the male target rating questionnaire with information on the factor loadings for each item and the Cronbach's alpha for each subscale

\begin{tabular}{llcc}
\hline Scale & \multicolumn{1}{c}{ Item } & Loading & $\begin{array}{c}\text { Cronbach's } \\
\text { alpha }\end{array}$ \\
\hline $\begin{array}{l}\text { Desirability for } \\
\text { a relationship }\end{array}$ & Willingness to enter a long-term relationship & .91 & .93 \\
& Willingness to introduce the female to his family & .88 & \\
& Willingness to enter a short-term sexual & .85 & \\
& relationship & & \\
& Willingness to introduce the female to his friends & .82 & \\
& Predicted spend on a first date & .58 & .91 \\
& Predicted likelihood that he would be faithful & .48 & \\
\hline Possession of & Faithful & .89 \\
desirable & Conscientious & .87 & \\
personality & Trustworthy & .85 & \\
traits & Agreeableness & .73 & \\
& Openness & .62 & \\
& Feminine & .59 & \\
& Extraverted & .59 & \\
\hline Promiscuity & Promiscuous & .86 & \\
& Flirtatious & .78 & \\
& Sexually experienced & .53 & \\
& Likelihood that he would be jealous if she spent & .53 & \\
\hline
\end{tabular}

\section{Female observers}

74 heterosexual women were recruited from the University of Northumbria. The age of female observers was 22.65 (range 18-58, SD 7.44). Participants were presented with a booklet containing colour facial photographs of target women (sized $29 \mathrm{~cm} \times 20 \mathrm{~cm}$ ) and asked to rate the target's physical attractiveness on a scale of 1-7 and then on 23 items relating to their perceptions of these women and predicted behaviour towards her. The items presented to female observers differed from those presented to male observers described above.

A second principal components factor analysis with Varimax rotation conducted on the 23 items presented to female observers identified four factors from which four sub-scales were devised. The first factor contained 6 items including flirtatious and sexual experience and measured overall promiscuity. The second factor contained 6 items, including trustworthy and conscientious, and measured the possession of desirable personality traits. The third factor contained 5 items, including introduce the target to family and friends, and it measured the willingness to integrate the woman within her social group. The fourth factor contained 3 items and measured the specific threat a woman poses to the current relationship, including that she would be interested in your partner, and you would be jealous if she spent time with your partner. These factors explained $29 \%, 27 \%$, 
$18 \%$ and $9 \%$ of rating variance respectively. See Table 2 for full details of each sub-scale. In both cases, rotation did not significantly alter the factors produced.

Table 2. Subscales derived from the female target rating questionnaire with information on the factor loadings for each item and the Cronbach's alpha for each subscale

\begin{tabular}{llcc}
\hline Scale & Flirtatious & Loading & $\begin{array}{c}\text { Cronbach's } \\
\text { alpha }\end{array}$ \\
\hline Promiscuity & $\begin{array}{l}\text { Extraverted } \\
\text { Sexually experienced }\end{array}$ & .75 \\
& Promiscuous & .91 & \\
& Feminine & .90 & \\
& Masculine & .81 & .92 \\
Possession of & Trustworthy & .78 & \\
desirable personality & Agreeable & .66 & \\
traits & Conscientious & .95 & \\
& Faithful & .91 & .88 \\
& Openness & .82 & \\
& You would reveal information to her & .78 & \\
& about your relationship & .73 & \\
\hline Willing to introduce & You would criticise her behaviour & .85 & \\
the woman within & Introduce this female to your partner & .82 & \\
her social group & Introduce this female to your family & .79 & \\
& You would criticise her appearance & .75 & \\
& Introduce this female to other friends & .71 & \\
\hline Specific threat a & She would be interested in your partner & .72 & \\
woman poses to a & She would actively encourage your & .69 & \\
relationship & partners advances & & \\
& You would be jealous if she spent time & .66 & \\
\hline & with your partner & & \\
\hline
\end{tabular}

\section{RESULTS}

\section{Descriptive statistics}

Male-rated target attractiveness was 3.11 (range 1.24-5.36, SD .84). Female-rated target attractiveness was 3.50 (range 1.42-5.54, SD .88). Men and women agreed on the attractiveness of target photographs $(r=.89, p<.05)$. In the present study, the age of the female target was not related to male-rated $(r=-.11, N S)$, or female rated attractiveness $(r=-.13, N S)$, perhaps due to the restricted age of female targets. As a woman's physical attractiveness is related to her age and fertility (Buss 1987) all correlations reported below controlled for the age of female targets. 


\section{Men's perception of female targets}

Attractiveness was significantly and positively related to the judged possession of desirable personality traits $(r=.64, p<.05)$, desirability for a relationship $(r=.80$, $p<.05)$, and promiscuity $(r=.77, p<.05)$.

A standard linear multiple regression showed that the three variables (desirable personality traits, desirability for relationships, and promiscuity) explained $76.40 \%$ (adjusted $\mathrm{R}^{2}$ ) of the variance in facial attractiveness ratings $\left(F_{3,79}=85.10, p<.05\right)$. The standardised regression coefficients show that all three variables significantly contributed to attractiveness ratings. Promiscuity accounted for the greatest proportion of variance (beta $=.47, p<.05$ ), followed by possession of desirable personality traits (beta $=.32, p<.05$ ) and desirability for a relationship (beta $=.25$, $p<.05$ ). All three variables were positively and significantly related to facial attractiveness ratings.

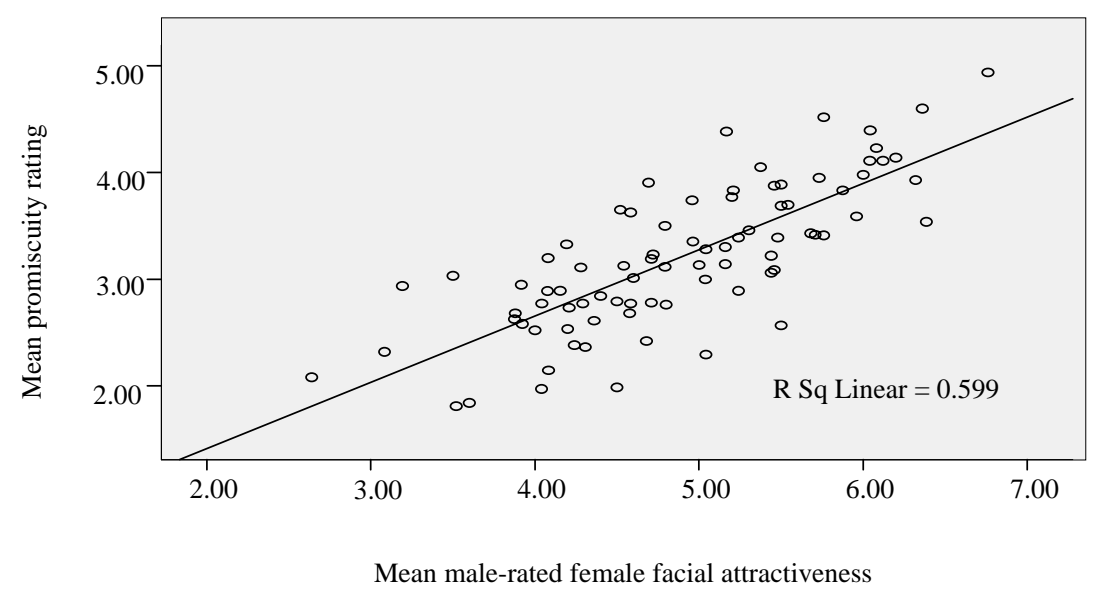

Figure 1. Correlation between mean male-rated female facial attractiveness and mean promiscuity ratings

Promiscuity and desirability for a relationship were highly correlated $(r=.78$, $p<.05)$, suggesting a high degree of colinearity. The standard multiple regression was repeated with these two measures entered as a composite. The two variables (desirable personality traits and the composite variable) explained $72.50 \%$ (adjusted $\left.\mathrm{R}^{2}\right)$ of the variance in facial attractiveness ratings $\left(F_{2,80}=108.92, p<.05\right)$. The composite measure accounted for the greatest proportion of the variance (beta $=$ $.70, p<.05)$ followed by the possession of desirable personality traits (beta $=.24$, $p<.05$ ), although both variables significantly contributed to attractiveness ratings. 


\section{Women's perception of female targets}

Facially attractive female targets were perceived by female observers as more likely to possess desirable personality traits $(r=.45, p<.05)$, be promiscuous $(r=.85$, $p<.05)$, and pose a specific threat to a current relationship $(r=.39, p<.05)$. Observers were more accepting of less physically attractive women within their existing social group $(r=-.28, p<.05)$.

A standard linear multiple regression showed that the four variables (possession of desirable personality traits, promiscuity, integrate within the social group and specific threat to a current relationship) explained $85.80 \%$ (adjusted $\mathrm{R}^{2}$ ) of the variance in facial attractiveness ratings $\left(F_{4,79}=126.17, p<.05\right)$. Promiscuity accounted for the greatest proportion of variance (beta $=.76, p<.05$ ), followed by possession of desirable personality traits (beta $=.40, p<.05$ ) and the specific threat posed to a relationship (beta $=.14, p<.05$ ). All three variables, however, were positively and significantly related to facial attractiveness ratings. Integration of the target within the social group did not significantly contribute to attractiveness ratings (beta $=-03, p<.05$ ).

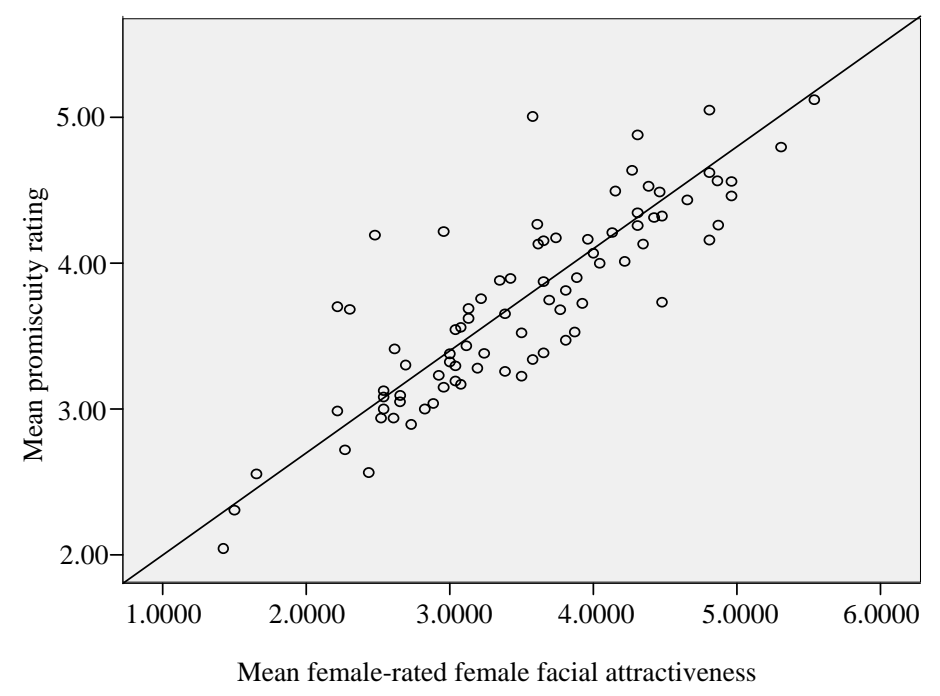

Figure 2. Correlation between mean female-rated female facial attractiveness and mean promiscuity ratings

A Fisher z-transformation revealed that physical attractiveness was most strongly related to female perceptions of target promiscuity $(\mathrm{z}=1.26)$ followed by male observer ratings of desirability for a relationship $(\mathrm{z}=1.10)$ and judged promiscuity $(\mathrm{z}=1.02)$. The association with facial attractiveness was considerably weaker for male perceptions of desirable personality traits $(z=0.76)$, female 
perception of desirable personality traits $(z=0.48)$, female observer perception of a specific threat $(\mathrm{z}=0.41)$ and female willingness to integrate the target within the social group $(\mathrm{z}=0.29)$.

\section{DISCUSSION}

The results indicate that both men and women judge attractive women as more likely than less attractive women to possess desirable personality traits and to be promiscuous. Thus there was both consistency in the attractiveness ratings of male and female observers, and consistency in the attribution of personality traits / predicted behaviour. In addition, men rate physically attractive women as more desirable for relationships and women judge physically attractive women to pose a greater threat to their current relationship and were less willing to integrate these women within their social group, although this relationship was weaker than that with the other variables. The present study benefited from the use of photographs rather than line drawings and other artificial stimuli often employed in this type of research (e.g. SINGH 1993, 1995). In addition, physical attractiveness was rated on a continuous rating scale rather than a forced choice rating of attractive or unattractive which cannot reflect the natural variation in physical attractiveness.

Male and female observers predicted that physically attractive targets were more likely to possess desirable personality traits than were less physically attractive women. This finding supports the 'What is Beautiful is Good' (DION et al. 1972), and 'halo' (NISBETT and WILSON 1977) effects, whereby attractive individuals are assumed to possess a greater number of socially desirable features. The halo effect is not a theoretically-driven finding, and the evolutionary advantage afforded by attributing desirable personality traits to attractive individuals is not clear. It is possible that this association encourages both men and women to interact with physically attractive women. For men, this may increase the opportunities for sexual access, for women this may allow greater monitoring of potential rivals. The finding that there is a consensus in the ratings of male and female observers (consistent with WIEDERMAN and HURST 1998) would further support a functional explanation of these inferences.

The finding that both male and female observers expect facially attractive female targets to be more promiscuous than less attractive women is consistent with previous research on attributions based on body shape (SINGH 2004). The finding that attractive women were expected to be promiscuous is also consistent with evidence that attractive people are judged as more likely to have an extramarital affair or request a divorce (DERMER and THIEL 1975), and that attractive women are perceived as less moral and more sexually provocative than less attractive women (ASHMORE, SOLOMAN and LONGO 1996). Physically attractive women are more desirable to prospective partners (Buss and BARNES 1986) and this attractiveness provides a reliable indication of their youth and fertility (BUSs 1987). Therefore physically attractive women would find it easier to secure a suitable partner than 
less attractive women. Although the majority of women are expected to favour long-term relationships with a high level of commitment, there are a number of advantages to short-term relationships (GREILING and BUSS 2000), for example access to resources or mates of superior genetic quality.

Although engaging in short-term relationships may lower a woman's overall mate value, this may not affect physically attractive women due to their continued physical desirability. The finding that men in the present study rated physically attractive women as more desirable for a relationship despite their apparent promiscuity supports this assertion. The fact that these women remain desirable for a relationship may suggest that the aim of inferring a woman's promiscuity is not to reject these women as potential partners. Instead, this inference could prompt behaviours such as mate guarding which may reduce the risk of cuckoldry. The correct identification of promiscuous women by women would allow the identification of rivals that pose the greatest threat, and women could adjust their monitoring or mate guarding behaviour accordingly. This is consistent with PENTON-VOAK et al. (2006) showing that people can accurately identify the personality traits of others. The finding that women in the present study rated physically attractive women as more likely to pose a specific threat to their current relationship and were less likely to accept and integrate them within their existing social group (despite the apparent possession of positive personality traits) supports this interpretation.

In conclusion, the findings suggest that while facially attractive women are rated as possessing desirable personality traits (in line with the halo effect), they are also rated as more promiscuous than less attractive women, by both male and female observers. The correct identification of sexually promiscuous women affords a number of evolutionary advantages. For men, this identification would encourage the appropriate selection of promiscuous women for short-term relationships and direct mate guarding behaviour if men select attractive women as long-term partners. For women, the identification of promiscuous females would aid the monitoring of women that present the greatest threat, or enable them to use mate retention techniques when appropriate.

\section{REFERENCES}

Ashmore, R. D., Soloman, M. R. and Longo, L. C. (1996): Thinking about fashion models: A multidimensional approach to the structure of perceived physical attractiveness. Personality and Social Psychology Bulletin, 22, 1083-1104.

BATEMAN, A. J. (1948): Intra-sexual selection in drosophila. Heredity, 2, 349-368.

Brewer, G. (2006): Patterns of physical attractiveness, self-rated attractiveness and sexual selection strategy in women. Unpublished doctoral dissertation, University of Central Lancashire, UK.

Buss, D. M. and BARNES, M. (1986). Preferences in human mate selection. Journal of Personality and Social Psychology, 50, 559-570. 
Buss, D. M. (1987): Sex differences in human mate selection criteria: An evolutionary perspective. In C. Crawford, D. KreBs and M. Smith (eds.) Sociobiology and Psychology: Ideas, Issues and Applications. New Jersey: Erlbaum.

Buss, D. M. and SchмiтT, D. P. (1993): Sexual strategies theory: An evolutionary perspective on human mating. Psychological Review, 100, 204-232.

ClARK, R. D. and HATFIELD, E. (1989): Gender differences in receptivity to sexual offers. Journal of Psychology and Human Sexuality, 2, 39-55.

DeRmer, M. and ThiEL, D. L. (1975): When beauty may fail. Journal of Personality and Social Psychology, 31, 1168-1176.

Dion, K., Berscheid, E. and Walster, E. (1972): What is beautiful is good. Journal of Personality and Social Psychology, 24, 285-290.

Eagly, A. H., Ashmore, R. D., MaKhiJani, M. J. and Longo, L. C. (1991): What is beautiful is good, but...: A Meta-analysis of research on the physical attractiveness stereotype. Psychological Bulletin, 110, 109-128.

Greiling, H. and Buss, D. M. (2000): Women's sexual strategies: The hidden dimension of extra-pair mating. Personality and Individual Differences, 28, 929-963.

Langlois, J. H., Kalakanis, L., Rubenstein, A. J., Larson, A., Hallam, M. and Snoot, M. (2000): Maxims or myths of beauty? A meta-analytic and theoretical review. Psychological Bulletin, 126, 390-423.

МiKACH, S. M. and BAILEY, J. M. (1999): What distinguishes women with unusually high numbers of sex partners? Evolution and Human Behavior, 20, 141-150.

NisBETT, R. and Wilson, T. D. (1977): The halo effect: Evidence for unconscious alteration of judgments. Journal of Personality and Social Psychology, 35, 250-256.

Penton-Voak, I. S., Pound, N., Little, A. C. and Perrett, D. I. (2006): Personality judgments from natural and composite facial images: More evidence for a 'kernel of truth' in social perception. Social Cognition, 24, 490-524.

SchmitT, D. P. and Buss, D. M. (2001): Human mate poaching: Tactics and temptations for infiltrating existing mateships. Journal of Personality and Social Psychology, 80, 894-917.

SingH, D. (1993): Adaptive significance of female physical attractiveness: Role of waist-to-hip ratio. Journal of Personality and Social Psychology, 65, 283-288.

SinGH, D. (1995): Female health, attractiveness, and desirability for relationships: Role of breast asymmetry and waist-to-hip ratio. Ethology and Sociobiology, 16, 465-481.

SinGH, D. (2004): Mating strategies of young women: Role of physical attractiveness. Journal of Sex Research, 41, 43-54.

Snyder, M., Berscheid, E. and TANKe, E. D. (1977): Social perception and interpersonal behaviour: On the self-fulfilling nature of social stereotypes. Journal of Personality and Social Psychology, 35, 656-666.

Trivers, R. L. (1972): Parental investment and sexual selection. In Sexual Selection and the Descent of Man 1871-1971. Chicago: Aldine.

Wiederman, M. W. and. HuRst, S. R. (1998): Body size, physical attractiveness, and body image among young adult women: Relationships to sexual experience and sexual esteem. Journal of Sex Research, 35, 272-281. 